\title{
Reduced proliferation and increased apoptosis of the SGC-7901 gastric cancer cell line on exposure to GDC-0449
}

\author{
CHUANQING WU ${ }^{1}$, JI CHENG ${ }^{1}$, SHAOBO HU $^{2}$, RUI DENG ${ }^{1}$, YAMBA WILLY MUANGU ${ }^{1}$, LIANG SHI $^{3}$, \\ KE WU ${ }^{1}$, PENG ZHANG ${ }^{1}$, WEILONG $\mathrm{CHANG}^{1}$, GUOBIN WANG $^{1}$ and KAIXIONG TAO ${ }^{1}$ \\ Departments of ${ }^{1}$ Gastrointestinal Surgery, ${ }^{2}$ Hepatobiliary Surgery and ${ }^{3}$ Clinical Laboratory, Union Hospital, \\ Tongji Medical College, Huazhong University of Science and Technology, Wuhan, Hubei 430022, P.R. China
}

Received January 31, 2015; Accepted November 19, 2015

DOI: $10.3892 / \mathrm{mmr} .2015 .4677$

\begin{abstract}
The sonic hedgehog (Shh) pathway is known to be vital in embryonic development and cancer propagation due to its irreplaceable role in cell proliferation and differentiation. GDC-0449, a basal cell skin cancer target drug approved by the Food and Drugs Administration, is a smoothened (Smo)-specific antagonist. Although it has been clinically verified as a valid drug for the treatment of skin and pancreatic cancer, the application of GDC-0449 in gastric cancer requires further investigation. In the present study, high-glucose Dulbecco's modified Eagle's medium with $10 \%$ fetal bovine serum was used for routine SGC-7901 cell line culture. A Cell Counting Kit- 8 assay was employed for determination of the reproductive rate of the cells. Flow cytometry was performed to determine the apoptosis status of the SGC-7901 cell line through Q4 analysis. Reverse transcription-quantitative polymerase chain reaction and Western blot analyses were used as target molecule detection vehicles. As expected, GDC-0449 reduced the expression levels of Shh-associated molecules, including Smo and gli1, compared with the blank group. The rate of cell proliferation was markedly limited and was accompanied by an increase in the apoptotic rate following GDC-0449 exposure. In addition, further investigations confirmed B cell lmyphoma-2 (Bcl-2) as the downstream molecular mechanism of GDC-0449 efficacy. Of note, representatives of the cancer stem cell (CSC) surface marker, CD44 and CD133, demonstrated a similar trend to the Smo restriction observed. By repressing the expression of Bcl-2, GDC-0449 inhibited the normal proliferation of SGC-7901 cells, and accelerated the apoptotic rate of the cells. It may also alter CSC properties due to the reduction in the expression of surface markers.
\end{abstract}

Correspondence to: Professor Kaixiong Tao, Department of Gastrointestinal Surgery, Union Hospital, Tongji Medical College, Huazhong University of Science and Technology, 1277 Jiefang Avenue, Wuhan, Hubei 430022, P.R. China

E-mail: tao_kaixiong@163.com

Key words: sonic hedgehog, smoothened, GDC-0449, SGC-7901, B cell lymphoma-2, gastric cancer

\section{Introduction}

Gastric cancer has become a nationwide epidemic due to changes in lifestyle and deterioration of the environment threatening human health. Gastric cancer has the second highest rate of incidence of cancer in males in China, and is one of the top five causes of cancer-associated mortality $(1,2)$. Due to its critical malignant properties and poor clinical prognosis, several investigations have been performed to identify curative therapies, with little success. Surgical resection at the early stage and chemotherapy at the late stages prevails as the current treatment strategy, which limits the amelioration of long-term efficacy $(3,4)$. The key to developing novel therapeutics is to clarify the molecular mechanisms underlying the development and expansion of cancer, which allow for specific targeted regimens, rather than less specific measures.

The sonic hedgehog (Shh) signaling pathway has increased in interest in the scientific community, owing to its potential in cancer (5-7). Shh is a highly-conservative pathway in mammals. The soluble ligand, Shh, is excreted into the extracellular matrix and makes contact with the trans-membrane receptor, Patched, which induces an inhibitory effect on the downstream smoothened (Smo) molecule. Subsequently, the released Smo transfers into the primary cilium, leading to an intracellular cascade and activation of Gli transcription factor family. Gli1 is a positive-regulator of cell proliferation as a result of stimulating the expression of downstream genes (8-11). It has been demonstrated that the inhibition of any component of the pathway results in early death and deformity, particularly for Smo and Gli1, indicating its possible role in controlling cancer growth $(12,13)$.

It is well-known that embryogenesis shares similar biological behavior with tumorigenesis in its pattern of cell proliferation and invasion $(14,15)$. The interplay between these two processes suggests the potential effect Shh may have on a neoplasm (16). Several studies have confirmed that the Shh pathway is abnormally activated in patients with cancer, and artificially induced inhibition of signaling leads to tumor narrowing (17-19). Following exposure to an Shh-antagonist, a decrease in pancreatic cancer malignancy was observed, in the form of proliferation restriction and apoptosis increase $(20,21)$. In addition, malignant hepatic carcinoma showed a similar reduction in progression as that observed in pancreatic 
cancer $(19,22,23)$. However, the association between gastric cancer and Shh signaling remains to be fully elucidated, warranting investigation of the interconnection of the two. Shh-targeted inhibitors may offer potential benefit for patients with gastric cancer, if theoretically and clinically approved.

GDC-0449 is an Smo antagonist, and its clinical superiority has been approved by the Food and Drug Administration (FDA) for the treatment of basal cell skin cancer $(24,25)$. The efficacy of GDC-0449 has been assessed in several types of solid tumor in vivo and in vitro $(25,26)$, although the effects in gastric cancer remain to be elucidated. Due to its promising anticancer effect in various tumors, the present study aimed to investigate whether GDC-0449 exerts similar effects in gastric cancer and examine the possible underlying mechanisms.

\section{Materials and methods}

Antibodies and reagents. Western blot detection reagents were purchased from Thermo Fisher Scientific, Inc. (Waltham, MA, USA). GDC-0449 was purchased from Selleck Chemicals (Houston, TX, USA). All other chemicals used in the present study were purchased from Invitrogen (Thermo Fisher Scientific, Inc.) and other domestic qualified providers.

Cell culture. The SGC-7901 cell line was obtained from American Type Culture Collection (Manassas, VA, USA) and cultured in high-glucose Dulbecco's modified Eagle's medium (DMEM; Thermo Fisher Scientific, Inc.) supplemented with $10 \%$ fetal bovine serum (FBS; Sijiqing Bio-engineering Co., Ltd., Hangzhou, China), and $1 \%$ penicillin and streptomycin (Thermo Fisher Scientific, Inc.) at $37^{\circ} \mathrm{C}$, in a humidified atmosphere of $95 \%$ air and $5 \% \mathrm{CO}_{2}$. Passages were used when the cultured cells were at stable status of $70-80 \%$ confluence. Routine renewal of culture medium and cell cryopreservation were managed in a standard, sterile environment.

Cell Counting Kit-8 (CCK-8) assessment. The SGC-7901 cell line was cultured in complete medium in a 96 -well plate (100 $\mu \mathrm{l}$ in each well) at a cell density of $1 \times 10^{5} / \mathrm{ml}$, and each group comprised five replicates. Following $24 \mathrm{~h}$ pre-culture, dimethyl sulfoxide (DMSO) and 5-50 $\mu \mathrm{M}$ GDC-0449 were added into the wells and co-cultured for 24-48 $\mathrm{h}$ prior to assessment. Subsequently, CCK- 8 reagent (Vazyme Biotech Co., Ltd., Nanjing, China) was added to the wells, and the optical density (OD) values were determined using a FLx800 ${ }^{\mathrm{TM}}$ Fluorescence Microplate Reader (BioTek Instruments, Inc., Winooski, VT, USA) after $4 \mathrm{~h}$. At a wavelength of $450 \mathrm{~nm}$, the OD values were counted and used to calculate the proliferation rate. A single replication plate was used at each time point, and the whole assessment was repeated at least three times.

Apoptosis assessment. The cells were incubated with complete medium at a cell density of $1 \times 10^{5} / \mathrm{ml}$. Following $24 \mathrm{~h}$ pre-culture, DMSO and GDC-0449 $(5,10,20$ and $50 \mu \mathrm{M})$ were added to the wells and co-cultured for 24 and $48 \mathrm{~h}$ prior to assessment. Subsequently $37^{\circ} \mathrm{C}$ trypsin (Beyotime Institute of Biotechnology, Haimen, China) was used for isolation, prior to three applications of centrifugation $(300 \mathrm{x} \mathrm{g}, 5 \mathrm{~min}$, $4^{\circ} \mathrm{C}$ ) and phosphate-buffered saline (PBS) washing steps to purify the cells. Annexin V-propidium iodide antibodies
(Nanjing KeyGen Biotech Co., Ltd., Nanjing, China) were added and incubated for $15 \mathrm{~min}$ at $25^{\circ} \mathrm{C}$. Flow cytometry (FACSCanto $^{\text {TM }}$ II; BD Biosceiences, San Jose, CA, USA) was then performed for the assessment of apoptosis, to calculate the percentage of cells in Q4, which indicates early apoptosis. The assays were performed in triplicate.

Western blot analysis. Cells grown in dishes were washed once in $\mathrm{PBS}$, and lysed in radioimmunoprecipitation assay buffer [50 mM Tris- $\mathrm{HCl}$ (pH 7.4), $150 \mathrm{mM} \mathrm{NaCl}, 1 \mathrm{mM}$ EDTA, $1 \%$ Triton $\mathrm{X}-100,1 \%$ sodium deoxycholate, $0.1 \%$ sodium dodecyl sulfate (SDS) and protease inhibitors] for $10 \mathrm{~min}$ on ice. After being cleared by centrifugation $(13,200 \mathrm{x} \mathrm{g}, 20 \mathrm{~min})$ at $4^{\circ} \mathrm{C}$, the protein concentrations were determined using a Bicinchoninic Acid Protein Assay kit. (Aspen Biological, Wuhan, China). The lysates (40 $\mu \mathrm{g}$ protein) were then mixed with protein loading buffer, separated by 8 or $10 \%$ SDS-polyacrylamide gel electrophoresis, and transferred to a nitrocellulose membrane (EMD Millipore, Billerica, MA, USA). A working dilution of the primary antibodies was made using $1 \%$ non-fat milk-PBS with Tween (PBST). The membrane was incubated with the diluted primary antibodies for $1 \mathrm{~h}$ at room temperature or overnight at $4^{\circ} \mathrm{C}$ with gentle agitation. The membrane was then washed in 1X PBST three times (10 min/wash) with agitation. Subsequently, the membrane was incubated for 1-2 $\mathrm{h}$ at room temperature in an appropriately diluted secondary antibody solution, prepared in the same blocking buffer as the primary antibody. The membrane was washed a further three times in 1X PBST (10 min/wash) with agitation. The chemiluminescent substrate (KPL, Gaithersburg, MD, USA) was prepared prior to use, according to the manufacturer's protocol. The membrane was incubated in the substrate as instructed by the manufacturer. The blots were then scanned (LiDE 110; Canon, Inc., Tokyo, Japan), and analyzed using ImageJ2 software (National Institutes of Health, Bethesda, MD, USA) All results were verified in triplicate. The primary antibodies used were as follows: Rabbit anti-human glyceraldehyde 3-phosphate dehydrogenase (1:10,000; cat. no. ab37168; Abcam, Shanghai, China); rabbit anti-human Gli1 (1:1,000; cat. no. sc-20687; Santa Cruz Biotechnology, Inc., Dallas, TX, USA); and rabbit anti-human Bcl-2 (1:1,000; cat. no. 2870S; Cell Signaling Technology, Inc., Danvers, MA, USA). The secondary antibody used was a peroxidase-conjugated goat anti-rabbit immunoglobulin G (H+L) (1:5,000; cat. no. 074-1506) purchased from Jackson ImmunoResearch Laboratories, Inc. (West Grove, PA, USA).

Reverse transcription-quantitative polymerase chain reaction $(R T-q P C R)$ assay. Total RNAs were extracted from the colon cancer cells using TRIzol reagent (Invitrogen; Thermo Fisher Scientific, Inc.) and reverse transcription was performed using PrimeScript RT Master mix (Takara Biotechnology, Co., Ltd., Dalian, China), according to the manufacturer's protocol. The cDNAs $(2 \mu \mathrm{l})$ were amplified in a $25 \mu \mathrm{l}$ reaction system using SYBR Premix Ex TaqTM (Takara Biotechnology, Co., Ltd.). Primers (10 $\mu \mathrm{M}$ each) specific for each of the signaling molecules were designed using NCBI/Primer-BLAST (http://blast.ncbi.nlm.nih. gov/Blast.cgi) and used to generate the PCR products. For the quantification of gene amplification, qPCR was performed 
A

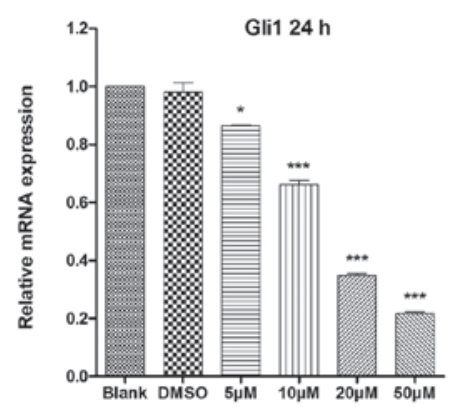

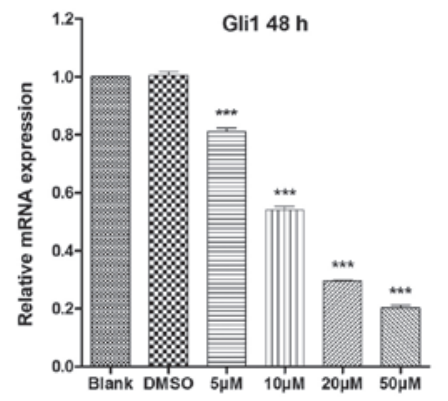

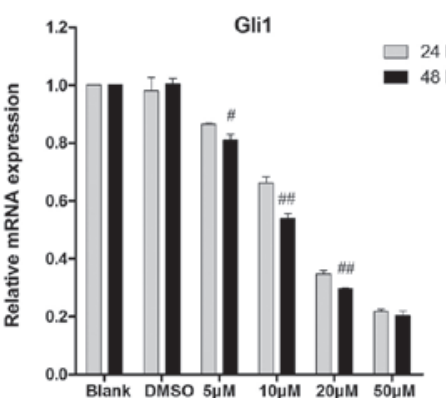

B

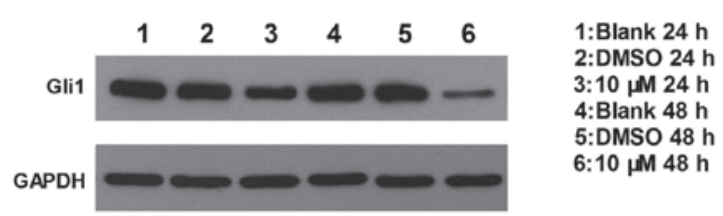

Figure 1. GDC-0449 inhibits sonic hedgehog signaling in the SGC-7901 cell line. (A) Reverse transcription-quantitative polymerase chain reaction analysis for detection of the expression of Gli1 in SGC-7901 cells treated with GDC-0449 (5-50 $\mu \mathrm{M})$ for 24 and 48 h. (B) Western blot analysis for the detection of the protein expression of Gli1 in SGC-7901 cells treated with GDC-0449 $(10 \mu \mathrm{M})$ for 24 and $48 \mathrm{~h}$. Results are representatives of three independent experiments and are expressed as the mean \pm standard deviation. ${ }^{*} \mathrm{P}<0.05$ and ${ }^{* * * *} \mathrm{P}<0.001$ vs. the adjacent group (e.g. $5 \mu \mathrm{M}$ group vs. the $\mathrm{DMSO}$ group); ${ }^{\sharp} \mathrm{P}<0.05$ and ${ }^{\# \#} \mathrm{P}<0.01$ vs. the $24 \mathrm{~h}$ group. DMSO, dimethyl sulfoxide.
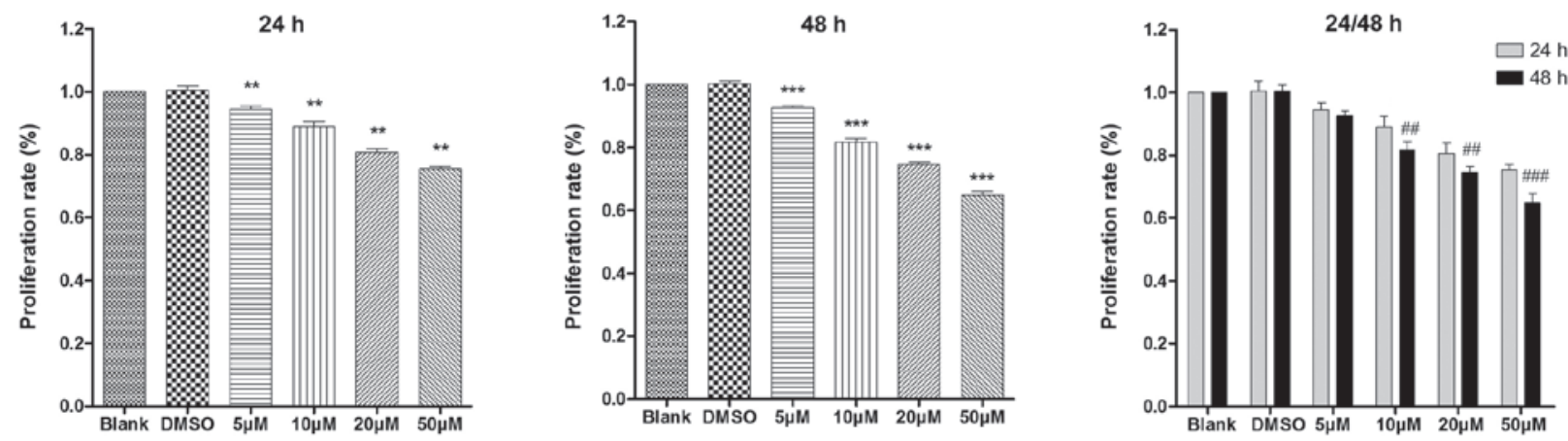

Figure 2. Proliferation rate of the SGC-7901 cell line declines in GDC-0449 exposure. The proliferation rate of the SGC-7901 cells following exposure to GDC-0449 $(5-50 \mu \mathrm{M})$ for 24 and $48 \mathrm{~h}$. All data were calculated from three independent Cell Counting Kit- 8 assays and are expressed as the mean \pm standard deviation. ${ }^{* *} \mathrm{P}<0.01$ and ${ }^{* * *} \mathrm{P}<0.001$ vs. the adjacent group (e.g. $5 \mu \mathrm{M}$ group vs. the DMSO group); ${ }^{\# \#} \mathrm{P}<0.01$ and ${ }^{\# \# \#} \mathrm{P}<0.001$ vs. the $24 \mathrm{~h}$ group. DMSO, dimethyl sulfoxide.

using an Applied Biosystems StepOnePlus ${ }^{\mathrm{TM}}$ Real-Time PCR system (Thermo Fisher Scientific., Inc.). The following gene specific primers were used: Smo forward 5'-CTGGTACGA GGACGTGGAGG-3' and reverse 5'-AGGGTGAAGAGC GTGCAGAG-3'; Gli1, forward 5'-TTCCTACCAGAGTCC CAAGT-3' and reverse 5'-CCCTATGTGAAGCCCTATTT-3'; CD44, forward 5'-GTAGTACAACGGAAGAAACA-3' and reverse 5'-TGTGAGATTGGGTTGAAGAA-3'; CD133, forward 5'-GCACTCTATACCAAAGCGTCAA-3' and reverse 5'-CACGATGCCACTTTCTCACT-3'; Bcl-2, forward 5'-GACTTCGCCGAGATGTCCAG-3' and reverse 5'-GGT GCCGGTTCAGGTACTCA-3'; $\beta$-actin, forward 5'-TCACCC ACACTGTGCCCATCTACG-3' and reverse 5'-CAGCGG AACCGCTCATTGCCAATGG-3'. Target sequences were amplified at $95^{\circ} \mathrm{C}$ for $10 \mathrm{~min}$, followed by 40 cycles of $95^{\circ} \mathrm{C}$ for $15 \mathrm{sec}$ and $60^{\circ} \mathrm{C}$ for $1 \mathrm{~min} . \beta$-actin was used as an endogenous normalization control. All assays were performed in triplicate and were calculated on the basis of $\Delta \Delta \mathrm{Cq}$. The $\mathrm{n}$-fold change in mRNA expression was determined according to the $2^{-\Delta \Delta \mathrm{Cq}}$ method (27).
Statistical analysis. The data in each group are expressed as the mean \pm standard deviation. Differences between groups were analyzed using one- or two-way analysis of variance using Prism 5 statistical analysis software (GraphPad Software, Inc., San Diego, CA, USA). P $<0.05$ was considered to indicate a statistically significant difference.

\section{Results}

GDC-0449 downregulates the Ssh pathway by antagonizing the activity of Smo. As described above, GDC-0449 is a Smo antagonist, which attenuates the progression of skin cancer and several types of solid tumor. The results of the RT-qPCR assays performed in the present study confirmed that the expression of Gli1 reduced markedly in the SGC-7901 cell line when treated with GDC-0449, which occurred in a dose(5-50 $\mu \mathrm{M})$ and time-dependent manner (Fig. 1A). A higher dose and longer exposure duration resulted in lower expression levels, and vice versa. Up to $70 \%$ of the expression level was restricted at the highest state of inhibition. Western blot 
A

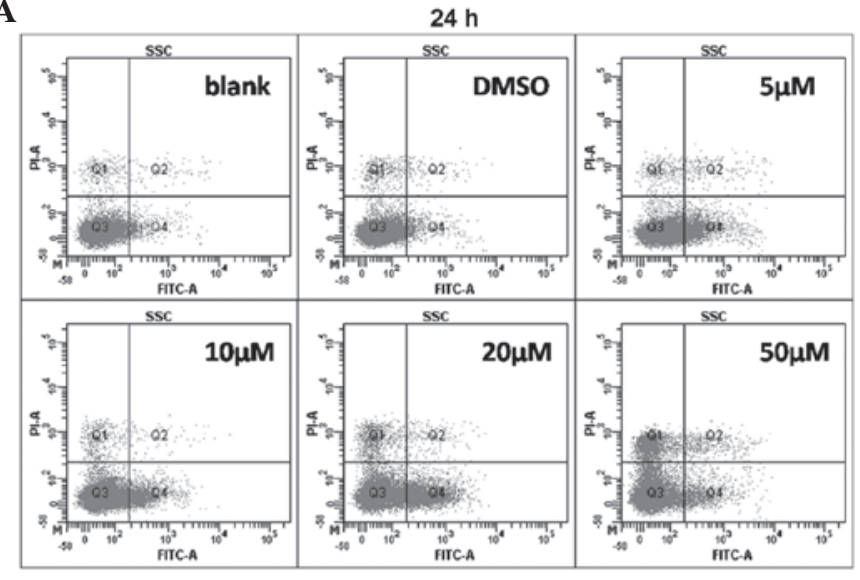

B

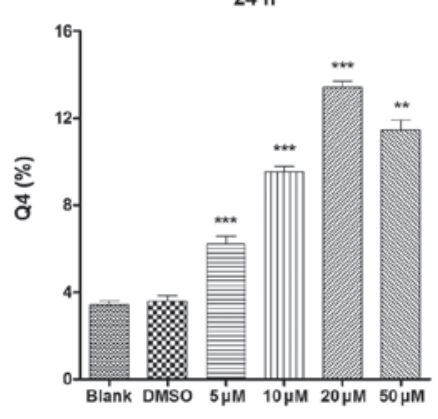

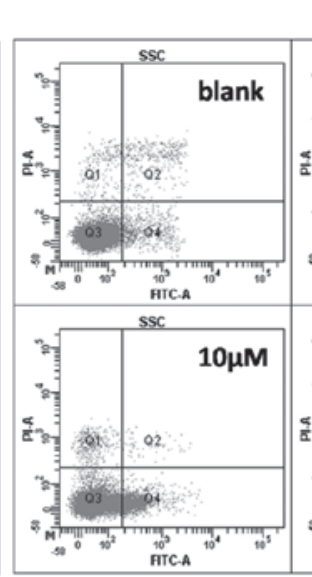
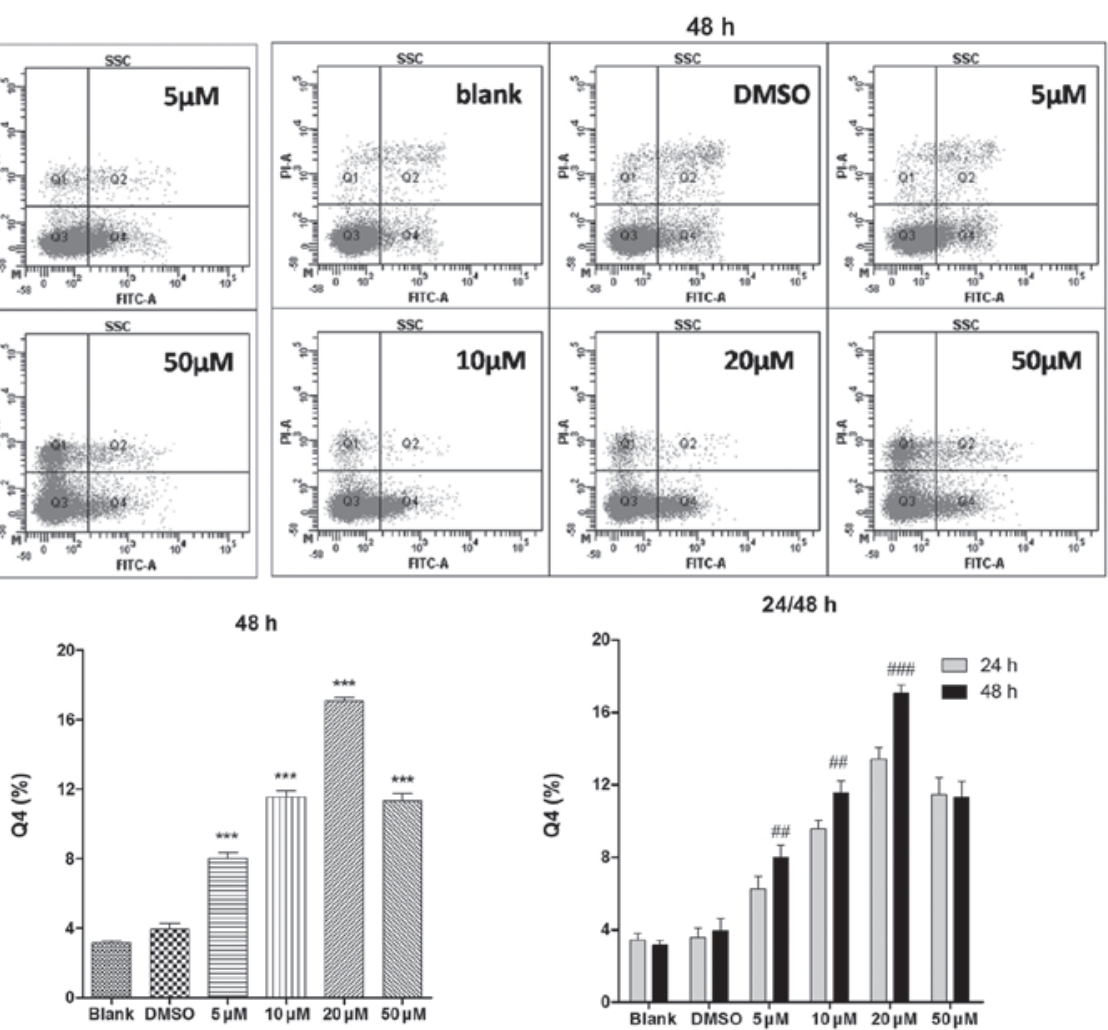

Figure 3. GDC-0449 increases the apoptotic ratio of SGC-7901 cells. (A) Cytometric diagrams following 24 and 48 h exposure to GDC-0449 (5-50 $\mu$ M). (B) Early apoptotic ratio (Q4\%) in SGC-7901 cells treated with GDC-0449 (5-50 $\mu \mathrm{M})$ for 24 and $48 \mathrm{~h}$. Results are representative of three independent experiments and are expressed as the mean \pm standard deviation. ${ }^{* *} \mathrm{P}<0.01$ and ${ }^{* * * *} \mathrm{P}<0.001$ vs. the adjacent group (e.g. $5 \mu \mathrm{M}$ group vs. the DMSO group); ${ }^{\# \#} \mathrm{P}<0.01$ and ${ }^{\# \# \#} \mathrm{P}<0.001 \mathrm{vs}$. the $24 \mathrm{~h}$ group. DMSO, dimethyl sulfoxide.
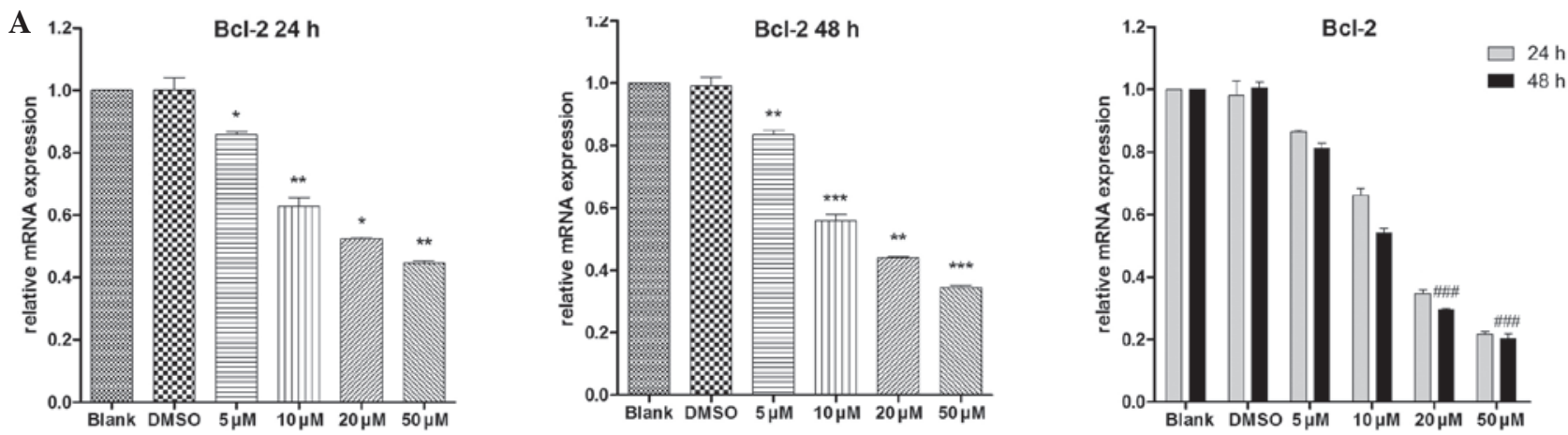

B

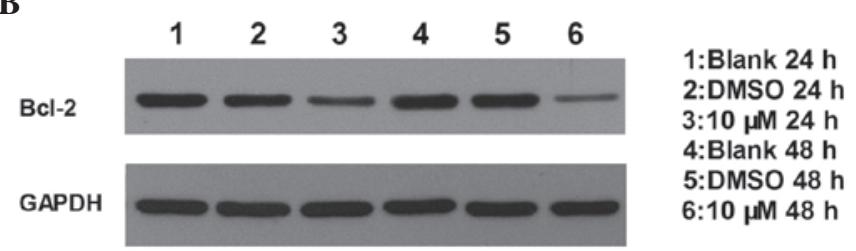

Figure 4. Expression of Bcl-2 decreases following exposure to GDC-0449. (A) Reverse transcription-quantitative polymerase chain reaction analysis was used for the detection of the expression of Bcl-2 in SGC-7901 cells exposed to GDC-0449 (5-50 $\mu \mathrm{M}$ ) for 24 and 48 h. (B) Western blot analysis was performed to detect the protein expression of Bcl-2 in SGC-7901 cells exposed to GDC-0449 (10 $\mu \mathrm{M})$ for 24 and $48 \mathrm{~h}$; Results are representative of three independent experiments and are expressed as the mean \pm standard deviation. ${ }^{*} \mathrm{P}<0.05,{ }^{* *} \mathrm{P}<0.01$ and ${ }^{* * *} \mathrm{P}<0.001$ vs. the adjacent group (e.g. $5 \mu \mathrm{M}$ group vs. the DMSO group); ${ }^{\# \#} \mathrm{P}<0.001$ vs. the 24 h group. DMSO, dimethyl sulfoxide; Bcl-2, B cell lymphoma-2.

analysis confirmed the inhibitory effects of $10 \mu \mathrm{M}$, compared with the control group (Fig. 1B). These findings indicated that GDC-0449 was a Smo antagonist and was used in the following experiments.
Cell reproduction rate is inhibited in the SGC-7901 cell line on GDC-0449 exposure. Shh signaling is vital for cell proliferation, therefore, the present study hypothesized that the Smo antagonist, GDC-0449, can reduce the proliferation 
A

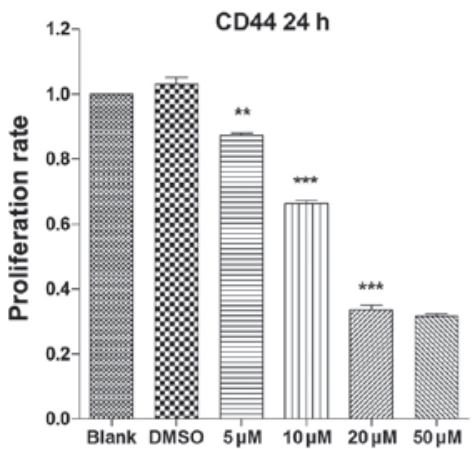

B

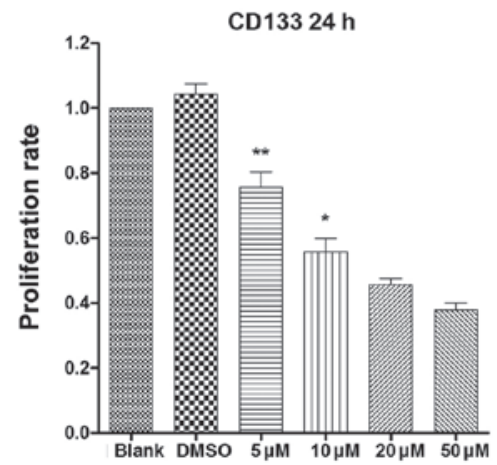

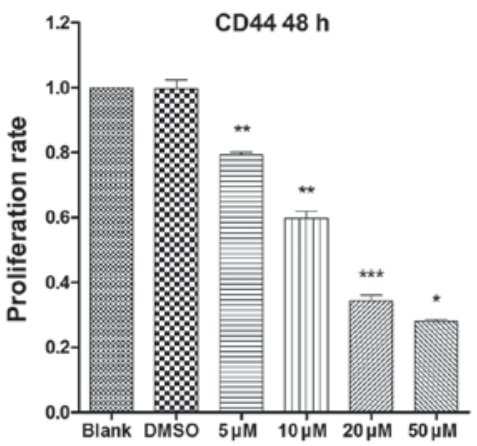
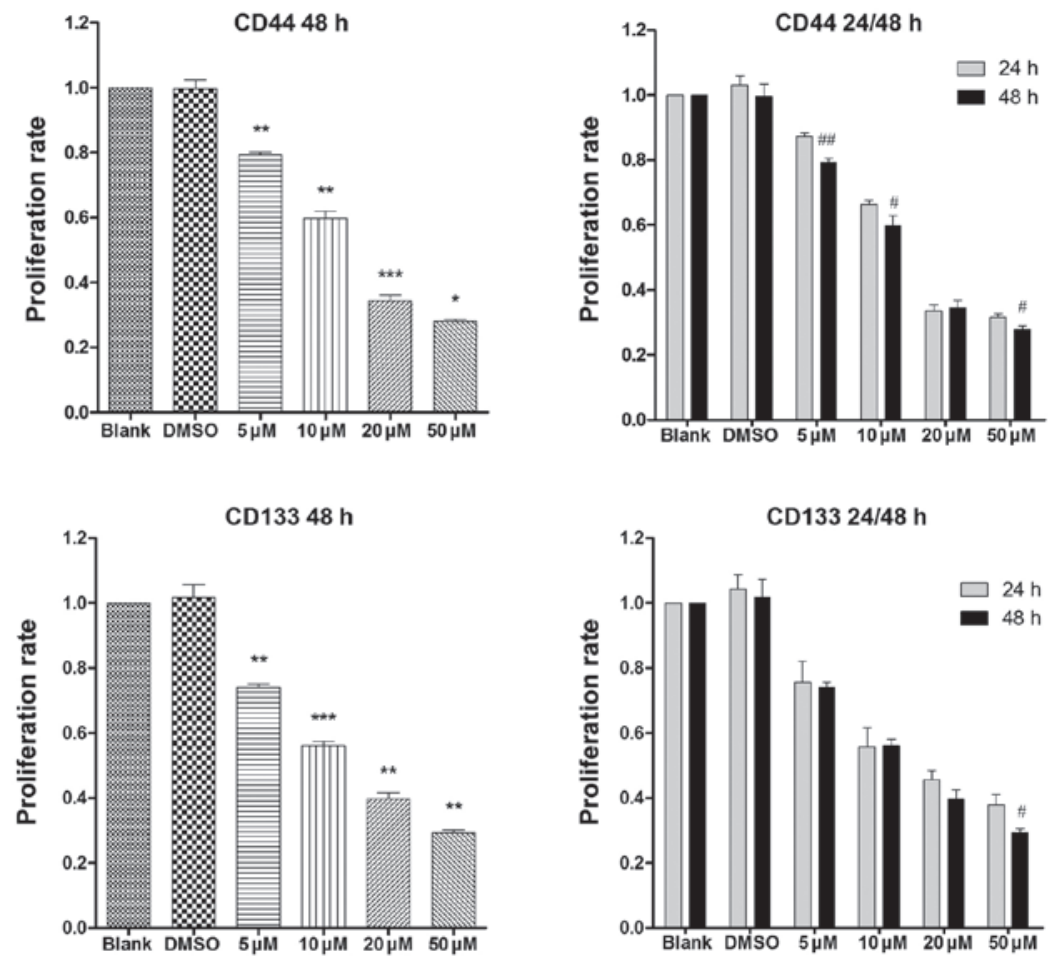

CD133 24/48 h

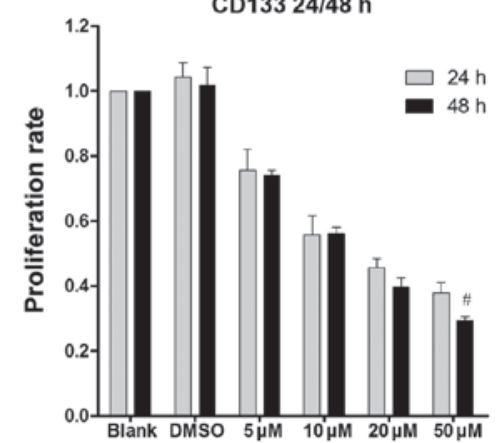

Figure 5. Expression levels of cancer stem cell markers decrease following exposure to GDC-0449. Reverse transcription-quantitative polymerase chain reaction analysis was performed to detect the expression levels of (A) CD44 and (B) CD133 in the SGC-7901 cells exposed to GDC-0449 (5-50 $\mu \mathrm{M}$ ) for 24 and 48 h. Results are representative of three independent experiments and are expressed as the mean \pm standard deviation. ${ }^{*} \mathrm{P}<0.05,{ }^{* *} \mathrm{P}<0.01$ and ${ }^{* * *} \mathrm{P}<0.001 \mathrm{vs}$. the adjacent group (e.g. $5 \mu \mathrm{M}$ group vs. the DMSO group); ${ }^{\#} \mathrm{P}<0.05$ and ${ }^{\# \#} \mathrm{P}<0.01$ vs. the $24 \mathrm{~h}$ group. DMSO, dimethyl sulfoxide.

of the SGC-7901 cell line. A notable decrease in cell proliferation rate was observed following 24 and $48 \mathrm{~h}$ exposure of the SGC-7901 cell line to GDC-0449 (Fig. 2). In further data analysis, $48 \mathrm{~h}$ exposure restricted cell growth more markedly, compared with that observed at $24 \mathrm{~h}$ (Fig. 2). The highest dose suppressed over half of the reproduction rate observed in the blank group.

GDC-0449 increases the apoptotic rate of the SGC-7901 cell line. The inhibitory effect on growth, described above, led to the investigation of whether the induction of apoptosis by GDC-0449 contributed to the apoptotic effect. Flow cytometry is the standard measure to calculate apoptotic rate. The Q4 percentage refers to early apoptosis and provides a good representation of drug-induced apoptosis. As expected, an increase in the apoptotic rate was observed in the SGC-7901 cell line, in a dose- and time-dependent manner following GDC-0449 exposure (Fig. 3). In contrast to the results of the CCK-8 test, a $50 \mu \mathrm{M}$ dose led to a reduction in the early apoptotic rate, compared with the rate at $20 \mu \mathrm{M}$, with a higher ratio of necrosis, suggesting that $20 \mu \mathrm{M}$ may represent the peak anti-apoptotic efficacy, rather than $50 \mu \mathrm{M}$ (Fig. 3), which exerted a more toxic effect. This result may partially explain the antigrowth efficacy of GDC-0449.

Bcl-2 is a downstream target of GDC-0449. Bcl-2 is a widely investigated confirmed anti-apoptoric gene, which is involved in different procedures of cell fate determination. The pro-apoptotic activity of GDC-0449, described above, suggested that Bcl-2 may contribute to this effect. RT-qPCR (Fig. 4A) and western blot (Fig. 4B) analyses were performed to confirm this hypothesis by determining the expression levels of RNA and protein. The expression level of Bcl-2 was reduced in a dose-dependent manner. At the peak level of inhibition, over half of the expression was decreased, which demonstrated the critical role Bcl-2 may have in the GDC-0449's downstream target.

Cancer stem cell surface markers share inhibitory effects with Smo. CD133 and CD44 have been recognized as gastric cancer stem cell surface markers. Markers represent the status and stem-ness of the cells. No previous studies have reported the latent association between GDC-0449 and surface markers. In the present study, the compelling RT-qPCR data showed a notable decline in the expression of surface markers in a dose- and time-dependent manner, compared with the blank group (Fig. 5). These results suggested that GDC-0449 and the Ssh signaling may affect cancer stem cells via a specific pathway, which remains to be elucidated.

\section{Discussion}

Gastric cancer has the highest incidence and cancer-associated mortality rates of all types of cancer of the digestive system (28). At present, there are no targeted treatment regimens, limiting the improvement of 5-year survival rates in patients with advanced disease (29). Several clinicians and researchers have devoted substantial efforts to improving treatment of the malignancy.

The Ssh pathway has been actively investigated, in terms of its regulation of embryonic growth, and is key in tissue differentiation and in the formation of the central nervous 
system in mammals (30-32). As the expansive proliferation of cancer cells is similarity to that of embryonic development, the critical role of Shh in cell proliferation and differentiation has led to it being associated with tumorigenesis in cancer. Previously published evidence has indicated an interaction between Ssh signaling and tumor malignancies. In almost every type of solid tumor, marked abnormal activation of the Ssh pathway exists, often in contrast to the reduced expression levels observed among normal differentiated tissues $(33,34)$. Previous studies have demonstrated that Shh-target treatment conveys superior antitumor value in skin cancer, and several types of solid tumors are in accordance with its theoretical mechanisms $(21,35-37)$. This has led it to become a focal area of investigation for oncologists and pharmacologists.

GDC-0449 has risen in prominence as a novel Smo inhibitor. Owing to its clinical approval by the FDA for the treatment of basal cell carcinoma, GDC-0449 provides superior effects, compared with its relatives in the Shh-antagonist family in terms of its medical efficacy $(38,39)$. According to in vivo and in vitro assays, pancreatic cancer is also affected by the GDC-0449, indicating a probable assault in digestive tumors as well $(24,40,41)$. The fundamental preliminary experiments in the present study also exhibited clinical excellence in treating colon cancer cells. Taken together, the present study on gastric cancer provided significant and timely results, indicating the irreplaceable role of the 'Shh-Smo-Gli' pathway and the underlying antagonist in gastric cancer. Further investigation of the downstream mechanisms identified Bcl-2 as a target site for GDC-0449, required to exert its functions.

However, a convincing and comprehensive set of results includes in vivo and in vitro confirmation, regardless of successful but restricted in vitro outcomes. Consequently, more detailed assays are required to obtain these data, with the aim of providing potential clinical benefit in the future.

Cancer stem cells have attracted attention in the scientific community. Ssh signaling is considered to be involved in regulating the stem-ness of CSC (42). Tumor invasiveness, relapse and metastasis are markedly associated with CSC (43). The suppression of CSC and its natural properties may reduce malignancy and improve patient prognosis. This interplay between Ssh signaling and cancer stem cells requires further investigation. In the present study, CD133 and CD44, which are surface markers of gastric cancer stem cells, showed significantly reduced expression levels in the SGC-7901 cell line following exposure to GDC-0449, indicating that GDC-0449 and the Ssh signaling pathway may affect the maintenance of gastric cancer stem cells.

In the present study, GDC-0449 demonstrated similar antitumor efficacy in the SGC-7901 cell line as skin and pancreatic cancer. In a dose- and time-dependent manner, exposure to GDC-0449 reduced the normal replication of the cells and triggered apoptosis in a destructive manner. The anti-apoptotic Bcl-2 gene was identified as a downstream target of GDC-0449 in the repression of expression. Furthermore, the effects on the CSC surface markers indicates the requirement to investigate potential mechanisms underlying the interactions of GDC-0449 and Shh with cancer stem cells. The results of the present study confirm that GDC-0449 may be a suitable candidate for use in gastric cancer therapy, and may benefit future patients.

\section{Acknowledgements}

The authors would like to thank all team members for methodological guidance and support. The authors would also like to thank Dr Guangchun Jin (Department of Medicine, Columbia University Medical Center, New York, NY, USA) for his advice and instruction. This study was supported by the National Natural Science Foundation of China to KaiXiong Tao (grant .no. 81172294) and the Research Fund of Public Welfare in the Health Industry (grant no. 201202015) and the Health and Family Plan Committee of China, 2014.

\section{References}

1. Anderson WF, Camargo MC, Fraumeni JF Jr, Correa P, Rosenberg PS and Rabkin CS: Age-specific trends in incidence of noncardia gastric cancer in US adults. JAMA 303: 1723-1728, 2010

2. Ferro A, Peleteiro B, Malvezzi M, Bosetti C, Bertuccio P, Levi F, Negri E, La Vecchia C and Lunet N: Worldwide trends in gastric cancer mortality (1980-2011), with predictions to 2015, and incidence by subtype. Eur J Cancer 50: 1330-1344, 2014.

3. Zhang WH, Chen XZ, Liu K, Chen XL, Yang K, Zhang B, Chen ZX, Chen JP, Zhou ZG and Hu JK: Outcomes of surgical treatment for gastric cancer patients: 11-year experience of a Chinese high-volume hospital. Med Oncol 31: 150, 2014.

4. Kwon IG, Cho I, Choi YY, Hyung WJ, Kim CB and Noh SH: Risk factors for complications during surgical treatment of remnant gastric cancer. Gastric Cancer 18: 390-396, 2015.

5. Vorechovský I, Benediktsson KP and Toftgård R: The patched/hedgehog/smoothened signalling pathway in human breast cancer: No evidence for H133Y SHH, PTCH and SMO mutations. Eur J Cancer 35: 711-713, 1999.

6. Romer $\mathrm{J}$ and Curran T: Targeting medulloblastoma: Small-molecule inhibitors of the Sonic Hedgehog pathway as potential cancer therapeutics. Cancer Res 65: 4975-4978, 2005.

7. Athar M, Li C, Kim AL, Spiegelman VS and Bickers DR: Sonic hedgehog signaling in Basal cell nevus syndrome. Cancer Res 74: 4967-4975, 2014.

8. Wang Y, Wang Y, Dong J, Wei W, Song B, Min H, Yu Y, Lei X, Zhao M, Teng W and Chen J: Developmental hypothyroxinemia and hypothyroidism reduce proliferation of cerebellar granule neuron precursors in rat offspring by downregulation of the sonic hedgehog signaling pathway. Mol Neurobiol 49: 1143-1152, 2014

9. Petrova E, Rios-Esteves J, Ouerfelli O, Glickman JF and Resh MD: Inhibitors of Hedgehog acyltransferase block Sonic Hedgehog signaling. Nat Chem Biol 9: 247-249, 2013.

10. Álvarez-Buylla A and Ihrie RA: Sonic hedgehog signaling in the postnatal brain. Semin Cell Dev Biol 33: 105-111, 2014.

11. Chen M, Qian Y, Dai J and Chu R: The sonic hedgehog signaling pathway induces myopic development by activating matrix metalloproteinase (MMP)-2 in Guinea pigs. PLoS One 9: e96952, 2014.

12. Schaefer GI, Perez JR, Duvall JR, Stanton BZ, Shamji AF and Schreiber SL: Discovery of small-molecule modulators of the Sonic Hedgehog pathway. J Am Chem Soc 135: 9675-9680, 2013.

13. Stanton BZ and Peng LF: Small-molecule modulators of the Sonic Hedgehog signaling pathway. Mol Biosyst 6: 44-54, 2010.

14. Woodland HR: Some studies on early embryonic development relevant to the study of cancer. J Clin Pathol Suppl (R Coll Pathol) 7: 26-30, 1974.

15. Martin GR: Teratocarcinomas as a model system for the study of embryogenesis and neoplasia. Cell 5: 229-243, 1975.

16. Omenetti A and Diehl AM: The adventures of sonic hedgehog in development and repair. II. Sonic hedgehog and liver development, inflammation and cancer. Am J Physiol Gastrointest Liver Physiol 294: G595-G598, 2008.

17. Batsaikhan BE, Yoshikawa K, Kurita N, Iwata T, Takasu C, Kashihara $\mathrm{H}$ and Shimada M: Cyclopamine decreased the expression of sonic hedgehog and its downstream genes in colon cancer stem cells. Anticancer Res 34: 6339-6344, 2014.

18. Li X, Wang Z, Ma Q, Xu Q, Liu H, Duan W, Lei J, Ma J, Wang X, Lv S, et al: Sonic hedgehog paracrine signaling activates stromal cells to promote perineural invasion in pancreatic cancer. Clin Cancer Res 20: 4326-4338, 2014. 
19. Chen JS, Huang XH, Wang Q, Huang JQ, Zhang LJ, Chen XL, Lei J and Cheng ZX: Sonic hedgehog signaling pathway induces cell migration and invasion through focal adhesion kinase/AKT signaling-mediated activation of matrix metalloproteinase (MMP)-2 and MMP-9 in liver cancer Carcinogenesis 34: 10-19, 2013.

20. Rosow DE, Liss AS, Strobel O, Fritz S, Bausch D, Valsangkar NP, Alsina J, Kulemann B, Park JK, Yamaguchi J, et al: Sonic Hedgehog in pancreatic cancer: From bench to bedside, then back to the bench. Surgery 152 (3 Suppl 1): S19-S32, 2012.

21. Rodova M, Fu J, Watkins DN, Srivastava RK and Shankar S: Sonic hedgehog signaling inhibition provides opportunities for targeted therapy by sulforaphane in regulating pancreatic cancer stem cell self-renewal. PLoS One 7: e46083, 2012.

22. Jeng KS, Sheen IS, Jeng WJ, Yu MC, Hsiau HI, Chang FY and Tsai HH: Activation of the sonic hedgehog signaling pathway occurs in the CD133 positive cells of mouse liver cancer Hepa 1-6 cells. Onco Targets Ther 6: 1047-1055, 2013.

23. Che L, Yuan YH, Jia J and Ren J: Activation of sonic hedgehog signaling pathway is an independent potential prognosis predictor in human hepatocellular carcinoma patients. Chin J Cancer Res 24: 323-331, 2012.

24. Amin SH, Tibes R, Kim JE and Hybarger CP: Hedgehog antagonist GDC-0449 is effective in the treatment of advanced basal cell carcinoma. Laryngoscope 120: 2456-2459, 2010.

25. Singh BN, Fu J, Srivastava RK and Shankar S: Hedgehog signaling antagonist GDC-0449 (Vismodegib) inhibits pancreatic cancer stem cell characteristics: Molecular mechanisms. PLoS One 6: e27306, 2011.

26. Karlou M, Lu JF, Wu G, Maity S, Tzelepi V, Navone NM, Hoang A, Logothetis CJ and Efstathiou E: Hedgehog signaling inhibition by the small molecule smoothened inhibitor GDC-0449 in the bone forming prostate cancer xenograft MDA PCa 118b. Prostate 72: 1638-1647, 2012.

27. Li QQ, Skinner J and Bennett JE: Evaluation of reference genes for real-time quantitative PCR studies in Candida glabrata following azole treatment. BMC Mol Biol 13: 22, 2012.

28. Yang L: Incidence and mortality of gastric cancer in China. World J Gastroenterol 12: 17-20, 2006.

29. Papenfuss WA, Kukar M, Oxenberg J, Attwood K, Nurkin S, Malhotra U and Wilkinson NW: Morbidity and mortality associated with gastrectomy for gastric cancer. Ann Surg Oncol 21: 3008-3014, 2014

30. De Luca A, Parmigiani E, Tosatto G, Martire S, Hoshino M, Buffo A, Leto K and Rossi F: Exogenous Sonic hedgehog modulates the pool of GABAergic interneurons during cerebellar development. Cerebellum 14: 72-85, 2015.
31. Lewis S: Neural development: Double agent sonic hedgehog. Nat Rev Neurosci 14: 666-667, 2013.

32. Courchet J and Polleux F: Sonic hedgehog, BOC and synaptic development: New players for an old game. Neuron 73: 1055-1058, 2012.

33. Xu X, Ding H, Rao G, Arora S, Saclarides CP, Esparaz J, Gattuso P, Solorzano CC and Prinz RA: Activation of the Sonic Hedgehog pathway in thyroid neoplasms and its potential role in tumor cell proliferation. Endocr Relat Cancer 19: 167-179, 2012.

34. Shaw A, Gipp J and Bushman W: The Sonic Hedgehog pathway stimulates prostate tumor growth by paracrine signaling and recapitulates embryonic gene expression in tumor myofibroblasts. Oncogene 28: 4480-4490, 2009.

35. Lin J, Wei L, Shen A, Cai Q, Xu W, Li H, Zhan Y, Hong Z and Peng J: Hedyotis diffusa Willd extract suppresses Sonic hedgehog signaling leading to the inhibition of colorectal cancer angiogenesis. Int J Oncol 42: 651-656, 2013.

36. Dahmane N, Lee J, Robins P, Heller P and Ruiz i Altaba A: Activation of the transcription factor Glil and the Sonic hedgehog signalling pathway in skin tumours. Nature 389: 876-881, 1997.

37. Fan H, Oro AE, Scott MP and Khavari PA: Induction of basal cell carcinoma features in transgenic human skin expressing Sonic Hedgehog. Nat Med 3: 788-792, 1997.

38. Dreno B, Basset-Seguin N, Caro I, Yue H and Schadendorf D: Clinical benefit assessment of vismodegib therapy in patients with advanced basal cell carcinoma. Oncologist 19: 790-796, 2014.

39. Yin VT, Sniegowski M and Esmaeli B: Indications and limitations of vismodegib for basal cell carcinoma. JAMA Ophthalmol 132: 905-906, 2014.

40. Kim EJ, Sahai V, Abel EV, Griffith KA, Greenson JK, Takebe N, Khan GN, Blau JL, Craig R, Balis UG, et al: Pilot clinical trial of hedgehog pathway inhibitor GDC-0449 (Vismodegib) in combination with gemcitabine in patients with metastatic pancreatic adenocarcinoma. Clin Cancer Res 20: 5937-5945, 2014.

41. Lorusso PM, Jimeno A, Dy G, Adjei A, Berlin J, Leichman L, Low JA, Colburn D, Chang I, Cheeti S, et al: Pharmacokinetic dose-scheduling study of hedgehog pathway inhibitor vismodegib (GDC-0449) in patients with locally advanced or metastatic solid tumors. Clin Cancer Res 17: 5774-5782, 2011.

42. Tang SN, Fu J, Nall D, Rodova M, Shankar S and Srivastava RK: Inhibition of sonic hedgehog pathway and pluripotency maintaining factors regulate human pancreatic cancer stem cell characteristics. Int J Cancer 131: 30-40, 2012.

43. Heiden KB, Williamson AJ, Doscas ME, Ye J, Wang Y, Liu D, Xing M,Prinz RA and Xu X: The sonic hedgehog signaling pathway maintains the cancer stem cell self-renewal of anaplastic thyroid cancer by inducing snail expression. J Clin Endocrinol Metab 99: E2178-E2187, 2014. 